\title{
Pathogenesis of Pasteurella multocida in Rabbits by Intra- nasal and Intra-ocular infection
}

Al-Najjar S. Sarhad

Department of Pathology and Poultry, Collage of Veterinary Medicine, Baghdad University.

\section{Accepted on-Feb-2011.}

\section{Summary}

In order to study the pathogenesis of the Pasteurella multocida in its natural rout of infection, this study was done to investigate and compare its pathogenesis after intranasal and intraocular infection.Thirty (30) rabbits were divided into three groups, the $1^{\text {st }}$ group $(n=12)$ infected with $240 \mathrm{CFU}$ of Pasteurella multocida intra-nasal, the $2^{\text {nd }}(n=12)$ infected with 240 CFU of $P$. multocida intra-ocular (eye drop), and the $3^{\text {rd }}$ group $(n=6)$ served as control negative. The animals were sacrificed if they did not die naturally at $24-48 \mathrm{hr}, 3$, 6, 9, 30 day post-infection (p.i.). The results showed dullness of the animals with nasal and ocular discharge and some animals dead at $48 \mathrm{hr}$ and $72 \mathrm{hr}$ p.i. (two animals from the $1^{\text {st }}$ group and four animals from the $2^{\text {nd }}$ group). The gross examination of the dead and sacrificed animals showed hemorrhage in the upper respiratory tract with fibrinous pleuropericaditis and emphysematous lung in the $1^{\text {st }}$ group, while the $2^{\text {nd }}$ group showed eye opacity and in some animal's eye swelling in addition to the feature noticed in the $1^{\text {st }}$ group. Pasteurella multocida was isolated from the organs of all the infected animals.The histopathological changes in the $1^{\text {st }}$ group were more intense than the $2^{\text {nd }}$ group and concenterated at the upper and lower respiratory tract as acute hemorrhagic treacheatis with fibrinous pneumonia, while the kidney showed hypercellularity of the glomeruli with cellular degeneration of renal tubule and lymphocytic hepatitis, also there is focal gliosis. Conclusion, intranasal infection was the effective route and the main pathological changes observed in the respiratory system characterized by fibrinous pleuropneumonia.

Keywords: Pasteurella multocida, Rabbit, intranasal, intraocular

E. mail: aloubaidysarhad@yahoo.com

\section{امراضية جرثومة Pasturella multocida في الارانب بالاصابة في داخل الانف و العين سرهد النجار \\ الخلاصة

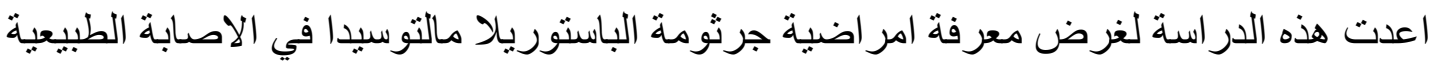

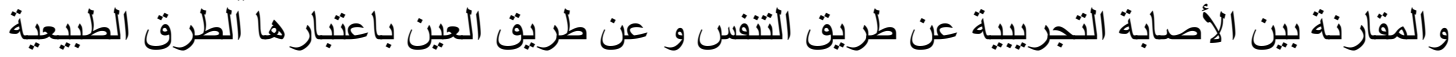

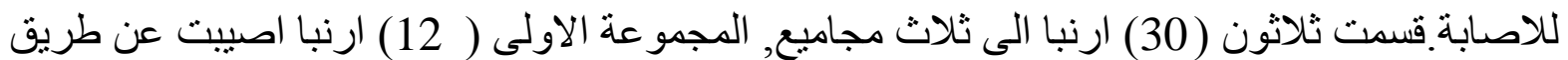

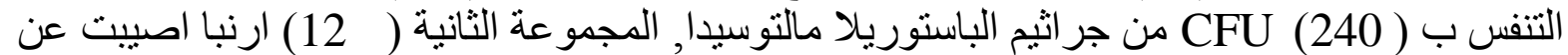

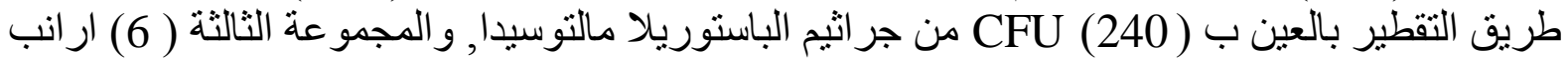

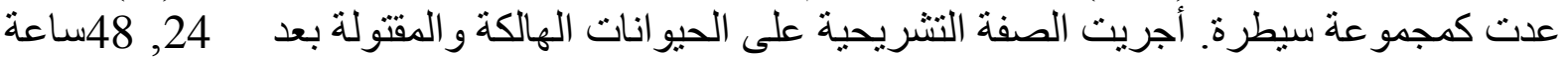

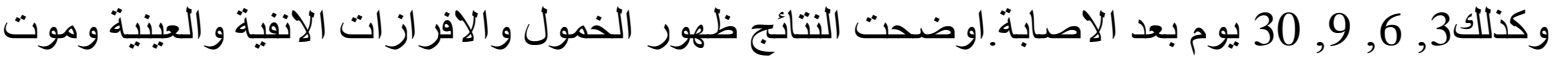

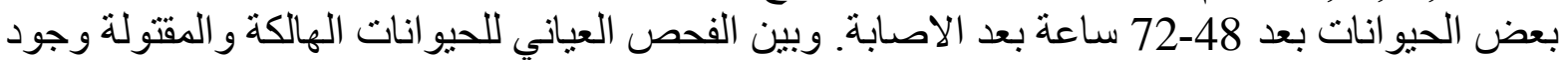




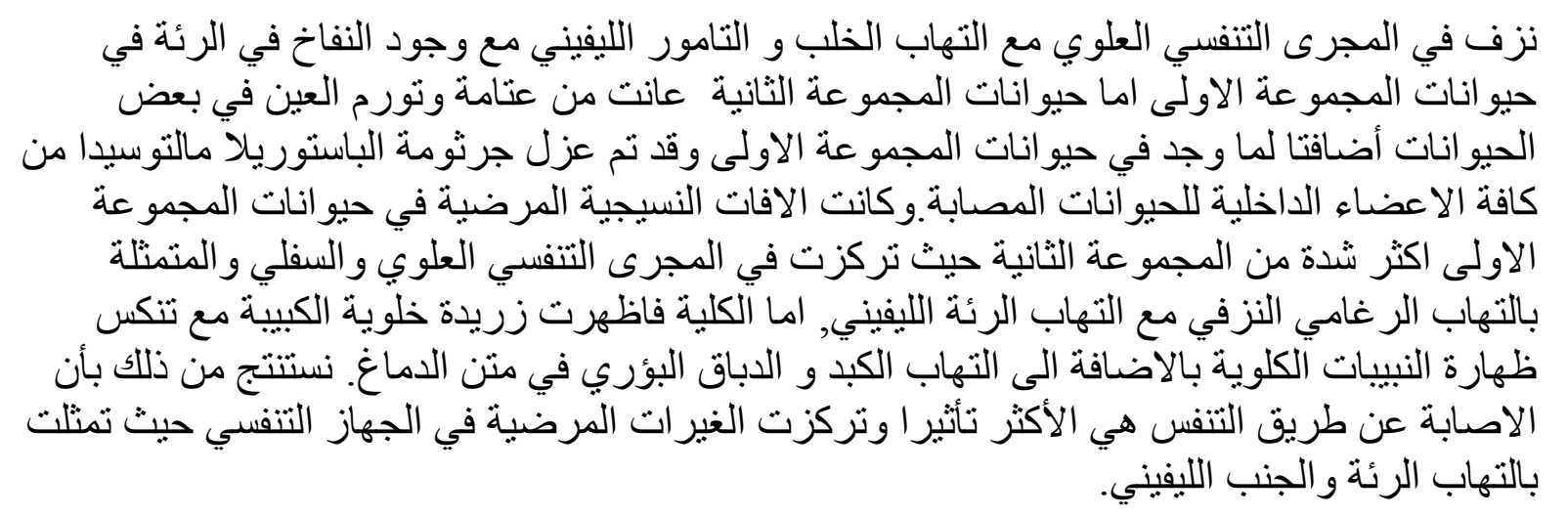

\section{Introduction}

The Gram-negative bacterium Pasteurella multocida exhibits a broad host range including most mammals, birds and also humans (1 and 2). Pasteurellosis is one of the most significant bacterial diseases of rabbits and one of the major causes of considerable economic loss in large production units throughout the world ( 3 and 4$)$. The disease is characterized by various clinical syndromes, e.g. respiratory distress, genital affections, abscesses and septicemia, but infection by P. multocida can also appear without any clinical signs manifested (5). The variability in clinical signs as well as the course of the disease may be influenced by different P. multocida virulence factors such as a capsule, fimbriae, lipopolysaccharides (endotoxin), dermonecrotoxin, neuraminidase etc. $(6,7,8,9$ and 10$)$.

Pasteurellosis in laboratory rabbits can cause acute epizootics of pneumonia with high morbidity and mortality. Chronic infection may result in rhinitis, bronchopneumonia, otitis media, pyometra, abscessation and encephalomyelitis (11).

The aim of the study was the comparsion of the pathogenicity by two types of infections route.

\section{Materials and methods:-}

1- Pasteurella multocida was obtained from Al-Kindy center for Veterinary Drugand Vaccines production, Baghdad, Iraq.

2- Experimental animals (rabbits) (30) were kept in animal house 2 weeks before the experiment for adaptation.

3- Histopathological slides were done according to(12)

4- Bacterial count was done according to Miles and Misra (13).

5- Experimental design: The animals were divided randomly into three groups:

a- $\quad$ The $1^{\text {st }}$ group (12 rabbits) were infected with $240 \mathrm{CFU}$ of P. multocida through. The nasal orifice. 
b- $\quad$ The $2^{\text {nd }}$ group (12 rabbits) were infected with $240 \mathrm{CFU}$ of P. multocida by eye drop.

c- Control negative group (6 rabbits) were injected of with sterile normal saline through nose.

The animals were sacrificed at 24 and $48 \mathrm{hr}, 3,6,9$, and 30 days post infection if not dead.

6- Bacterial isolation and culture were done on blood agar and trypton soya agar

7- Samples for pathological examination were taken.

\section{Results}

Clinical signs:The clinical signs observed were anoxia, dullness, fever, congestion of the conjunctiva, rapid respiration and nasal discharge, in the nasal infected group, while the ocular infected group showed enlargement of eye and inflammation in addition to the other signs observed on the $1^{\text {st }}$ group. Some of the animals dead at $16 \mathrm{hr}$ and 3, 4 days post infection.

Bacterial isolation: The results showed that Pasteurella multocida was isolated from most of the examined internal organs of infected rabbits. The degree of bacterial isolates showed variations (very heavy, heavy, moderate, mild and very mild) according to periods of infection and organs. Lung, liver, spleen, lymph node, heart blood and kidney are the main organs which showed more extensive bacterial isolation (table: 1 and 2).

\section{Pathological examination: Gross examination :-}

The $\mathbf{1}^{\text {st }}$ group (nasal infected group):There was hemorrhage in the lumen of the upper respiratory tract (larynx and trachea) at $16 \mathrm{hr}$ to day 2 post infection (fig:1), there was white fibrinous exudates on the pericardium and pleura which reveled a fibrinous pleuropiricarditis with few white spotted foci on the lung surface with emphysematous areas (fig: 2) as well as solid pneumonic areas with adhesion between plural surface and the thoracic wall, while the liver andspleen were enlarged with rounded and maningeal congestion.

The $2^{\text {nd }}$ group (ocular infected group): Reveled eye opacity, congestion and excessive lacremation during $24 \mathrm{hr}$ and also same changes appeared in the $1^{\text {st }}$ group purities, congestion and thickening of menengies occurred at day 3 post infection.

\section{Histopathological results:}

First group:

Lung :- The microscopic examination of the lung tissue at $16 \mathrm{hrs}$ showed thickening of the alveolar wall due to congestion of the blood capillaries and edematous fluid in the alveolar lumen (fig: 3 ) while at day 2 post infection, the inflammatory cells mainly neutrophils and lymphocyte appeared in section in addition to the prior lesion and in $2^{\text {nd }}$ to the end of the experiment the blood vessels in the lung reveals hypertrophy of the tunica media and hyperplasia of 
the tunica intima (endothelial lining) in addition to the congestion (fig: 4) and fibriuouns exudates appear in the lung.

Trachea: - At 16 hrs post infection there was hemorrhage in the lumen of the trachea with congestion of the submucosa, while at day two. There was hemorrhages in the sub mucosa and also in the lumen of the trachea with inflammatory cells infiltration mainly neutrophils and lymphocytes (fig: 5) and at days 3 and 4 post infection the epithelial lining of the trachea suffered from sloughing and desquamation and there was inflammatory exudates in the lumen consisting of neutrophils and lymphocytes in addition to tissue debris (figures 6 and 7)

Liver :- At $16 \mathrm{hr}$ to day 2 there was blood vessels congestion mainly central vein and at day 3 there was inflammatory cells infiltrating liver parenchyma between hepatocytes and also around the central vein consisting mainly from neutrophils, lymphocytes and macrophage (fig: 8) and at day 6 there was multifocal aggregation of inflammatory cells mainly lymphocyte (figure 9).

Kidney: - At 16 hrs there was congestion of blood vessels and at the second day post infection reveals hypercellularity of the glomeruli with congestion of blood capillaries of the glomerular tuft (fig: 10) and also between renal tubules with mild proliferation of endothelial lining of B.V between renal tubules while at day 4 post infected in addition to the congestion there is hemorrhage between renal tubules, and lymphocytes infiltration in proximal renal tubules (fig: 11) and at day 6 post infection the lymphocytes and macrophages infiltrated between the collecting ducts with vacuolar degeneration of the epithelial lining of the renal tubules.

Heart :- At days 3 to 6 there was inflammatory cells infiltration between muscles fibers, and there was thickening of the endocardium layer due to hyperplasia of the endothelial cells lining and also fibrinous exudates in addition to inflammatory cells infiltration (fig: 12).

Brain:- 16 hrs post infection reveled perivascular edema and at day 2 to 3 post infection there was congestion of blood vessels in the manengies and inflammatory cells mainly lymphocyte (fig: 13) and also there was focal gliosis at day 4-6 pi. (fig: 14).

Spleen: Showed congestion and atrophic white pulp at day 4 pi.

Other tissue: The intestine showed inflammatory cells infiltration on the lamina propera and also in the lumen of the intestine and also the stomach showed inflammatory cells aggregation in the sub-mucosa.

\section{Second group:-}

Lung: At day 3 to 6 post infection the lung tissue reveled a severe congestion and edema, thickening of the inter alveolar wall and at days 9 to 29 post infection there was thickening of the inter alveolar septa due to inflammatory cells and fibranous exudates (fig: 15), in addition to focal aggregation of inflammatory cells mainly lymphocytes in some part of the lung. 
Trachea: - The trachea showed congestion at day 9 post infection, the submucosa infiltrated with inflammatory cells mainly lymphocytes and neutrophils.

Liver: Reveled severe congestion of blood vessel mainly central vein also the sinusoid that filled with blood with severe infiltration of polymorph-nuclear cells between swollen hepatocytes at day 3 to 9 post infection (fig: 16) while in day 29 post infection the neutrophils replaced by lymphocytes and macrophages with Kupffer cells proliferation.

Kidney: - At days 3 to 9 post infection the renal tubule epithelia suffered from acute cellular degeneration with hyper cellularty of the glomeruli and also there is moderate hyperplasia of the endothelial lining of the blood capillaries between renal tubules and diffuse inflammatory cells infiltration mainly lymphocyte between renal tubules and interstitial tissue (fig: 17), in addition to atrophy of some glomeruli (fig: 18).

Heart: Reveled inflammatory cells infiltration between muscles fiber at days 9 to 29 post infection (fig: 19).

Brain: - At days 6 to 9 post infection the brain tissue reveled congestion of blood vessels with perivasicular edema and congestion of meninges, with inflammatory cells infiltration (fig: 20)

Spleen: - Moderate lymphoid hyperplasia of the white pulp.

\section{Discussion}

Bacterial isolation: The results of study showed that the Pasteurella multocida isolated from different organs indicate the bacteremia and wide spread of the microorganism in the body and that's agreed with (14) who made experimental infection with Pasteurella multocida of field isolates to mice with intra peritoneal infection and isolated the bacteria from different organs ( 3 and 4). Bacteremia allows bacteria to spread widely in the body and permits them to reach tissue particularly suitable to their multiplication (15).

Pathological examination: The gross lesion of lung showed congestion and consolidation also there was adhesion between lung surface and pleura as well as with thoracic cavity, the lung showed foamy content which related to intra alveolar edema, this lesions agreed with (16 and 17).

The main histopathological changes have been seen in examined organ such as (liver, lungs, kidney, spleen and lymph node), there were extensive congestion, degeneration also these lesions associated with extensive infiltration of Inflammatory cells due to leukocytic recruitment as effect of bacterial infection on cell activation, and these recruited cells especially neutrophils were responsible for inducing parenchymal cell injury in the organs $(18,19,20$ and $21)$. The entire lesions noticed in all examined organs especially thickened connective tissue surrounding the blood vessels were agreed with (22) in their study of three elephants carcasses that die due to pasteurellosis. Present result revealed a fibrinous bronchopneumonia in the both groups that's agreed with (23) which reveals that the lung lesions comprised a fibrinous 
bronchopneumonia with variable sized areas of coagulative necrosis, extensive deposition of fibrin and massive dilatation and edema of the interlobular and pleural lymphatic, bronchopneumonia may be due to the erogenous route of infection (24). Hemorrhagic tracheatis was observed in this study due to attachment and proliferation of Pasteurella on the surface epithelium, While the ultra structural changes detected by study of (25) were deciliation or clumping of cilia of ciliated epithelium, cellular swelling, vacuolation and sloughing. The subepithelial capillaries showed congestion, intravascular fibrin deposition, platelets aggregation and endothelial injury. Pasteurella multocida was observed attached to the injured endothelial cells. Neutrophils, mast cells, vacuolated monocytes and macrophages infiltrated the lamina propria and between the degenerated epithelial cells.

Table (1): bacterial isolation from rabbit's organs of the $1^{\text {st }}$ group

\begin{tabular}{|l|l|l|l|l|l|}
\hline & liver & lung & Spleen & $\begin{array}{l}\text { Heart and } \\
\text { blood }\end{array}$ & kidney \\
\hline $\begin{array}{l}\text { Hrs16-2 } \\
\text { days }\end{array}$ & + & ++ & ++ & ++ & ++ \\
\hline 3 & +++ & ++++ & ++ & ++ & ++ \\
\hline 6 & ++++ & ++++ & ++ & +++ & +++ \\
\hline $\mathbf{6}$ & ++++ & ++++ & + & +++ & +++ \\
\hline 30 & +++ & +++ & + & ++ & ++ \\
\hline
\end{tabular}

Table (2): bacterial isolation from rabbit's organs of the $2^{\text {nd }}$ group

\begin{tabular}{|c|c|c|c|c|c|}
\hline & liver & lung & Spleen & $\begin{array}{l}\text { Heart } \\
\text { blood }\end{array}$ & and $\mid$ Kidney \\
\hline $\begin{array}{l}\text { Hrs16-2 } \\
\text { days }\end{array}$ & +++ & +++ & ++ & ++ & + \\
\hline 3 & ++++ & +++++ & ++ & +++ & ++ \\
\hline 6 & +++++ & +++++ & ++ & +++ & ++ \\
\hline 9 & +++++ & +++++ & + & ++++ & ++ \\
\hline 30 & +++ & +++ & + & ++ & ++ \\
\hline
\end{tabular}




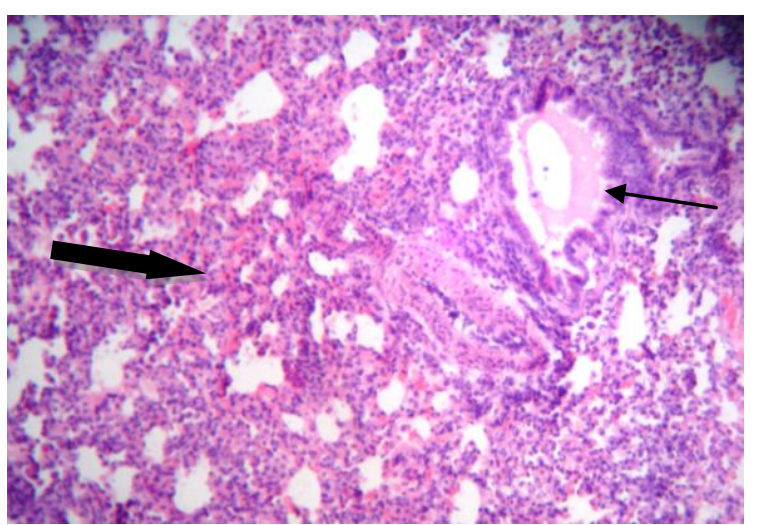

Fig (3):lung at $16 \mathrm{hr}$ P.I. showed congestion of the capillaries ( ) with odema in the lumen( ) ( H\&EX10).

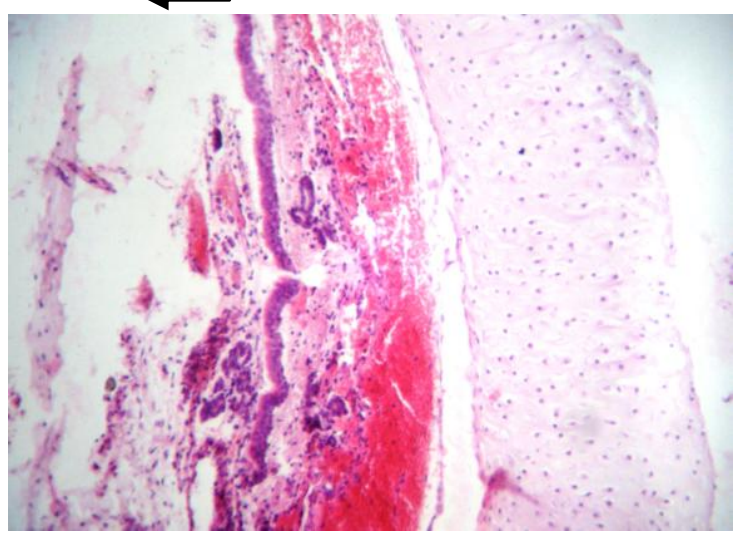

Fig (5): trachea at $16 \mathrm{hr}$ pi. showed hemorrhages in the sub mucosa \& also in the lumen with inflammatory cells infiltration mainly neutrophils \& lymphocytes( H\&EX10).

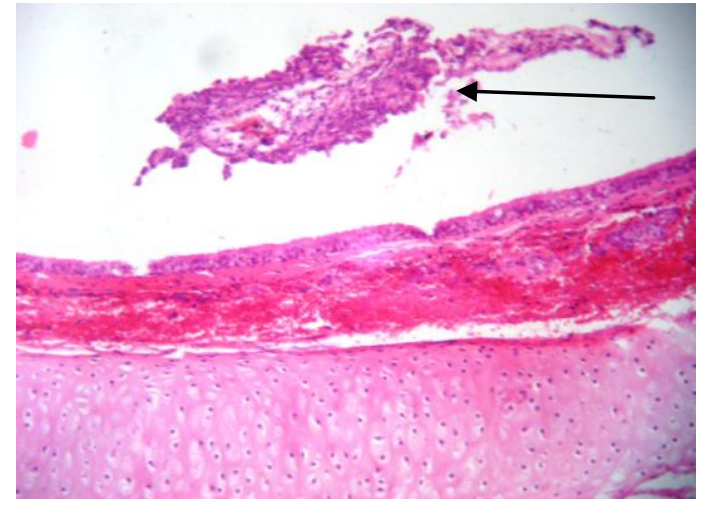

Fig (7): trachea at day 3 pi. showed inflammatory exudates in the lumen consist from neutrophils \& lympho cytes in addition to tissue deprise $(\leftarrow)$ ( H\&EX10).

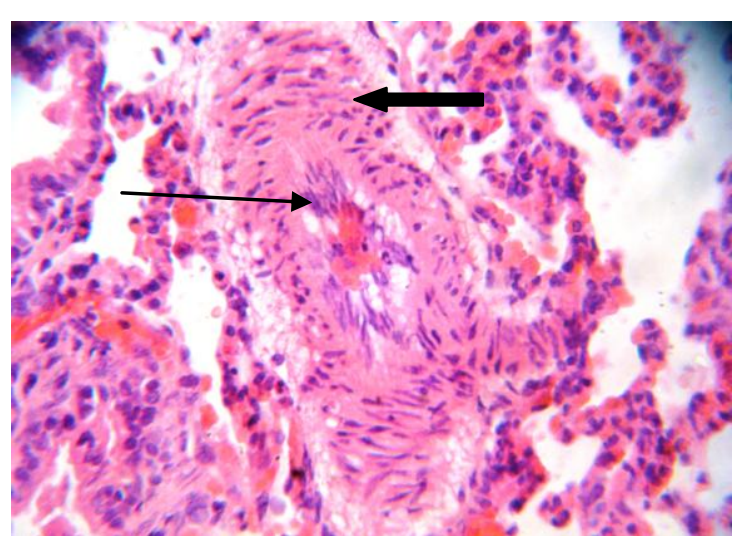

Fig (4): lung at day 6 pi. reveals hyperatrophy of the tunice maedia ( $)$ \& hyper plasia of the tunica antina $(\rightarrow)$ ( H\&EX40).

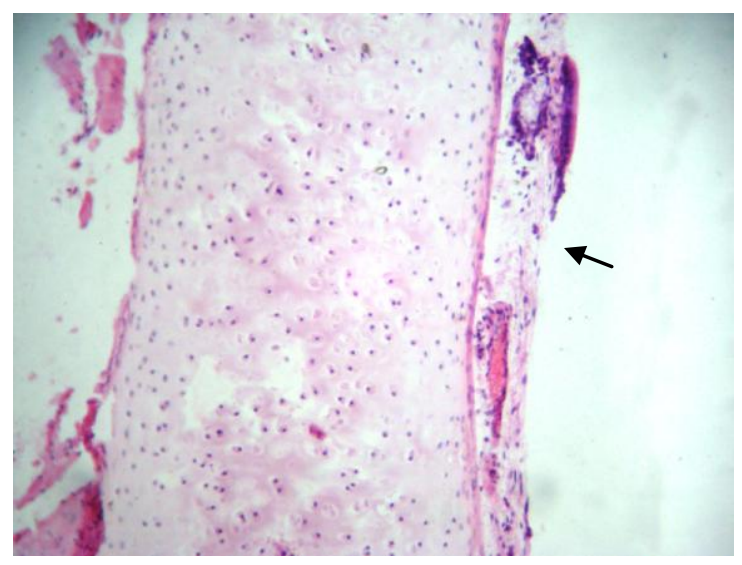

Fig (6): trachea at day 3 showed sloughing and desquamation of the epithelial lining

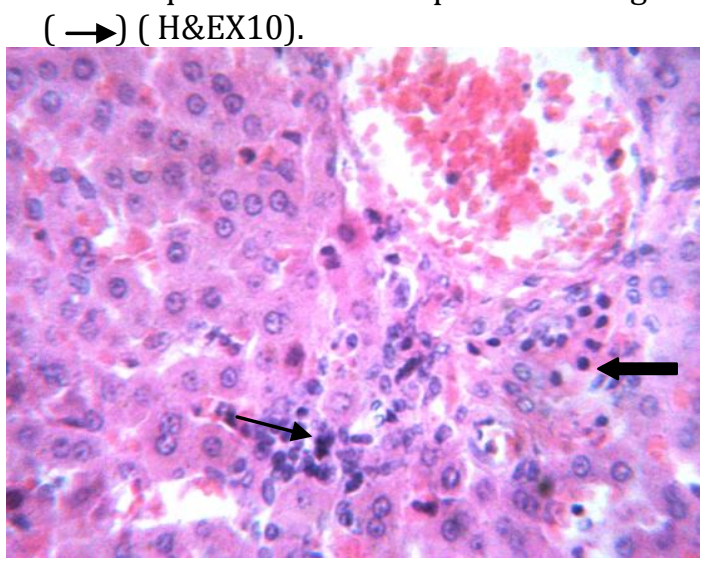

Fig (8) liver at day 3 pi. showed inflammatory cells infiltrated between hepatocytes and also around the central vein consist mainly from lymphocytes $(\rightarrow)$ and macrophage ( $)$ (H\&EX40). 


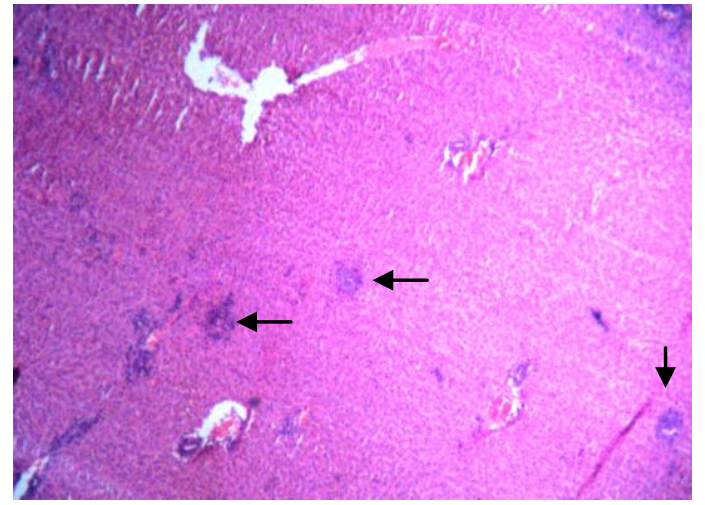

Fig (9): liver at day 6 reveals focal aggregation of inflammatory cells mainly lymphocyte $(\longleftarrow)(\mathrm{H} \& \mathrm{EX} 10)$.

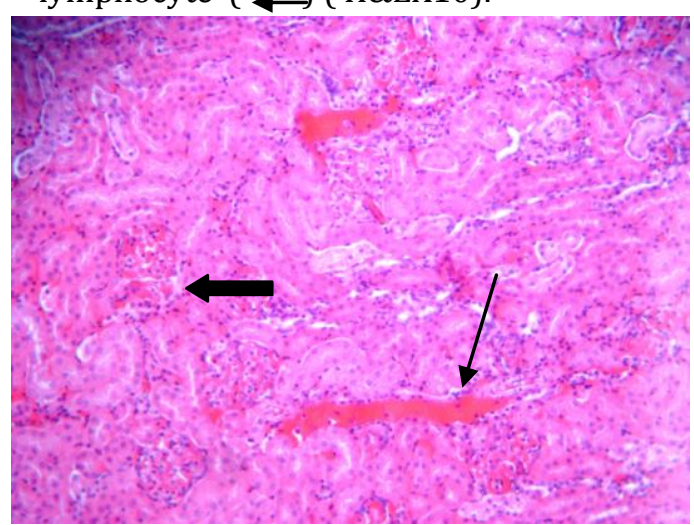

Fig (11): kidney at day 4 pi. revealed hemorrhage between renal tubules $(\leftarrow)$, and lymphocytes infiltration in proximal renal tubules ( $\omega$ ) ( H\&EX10).

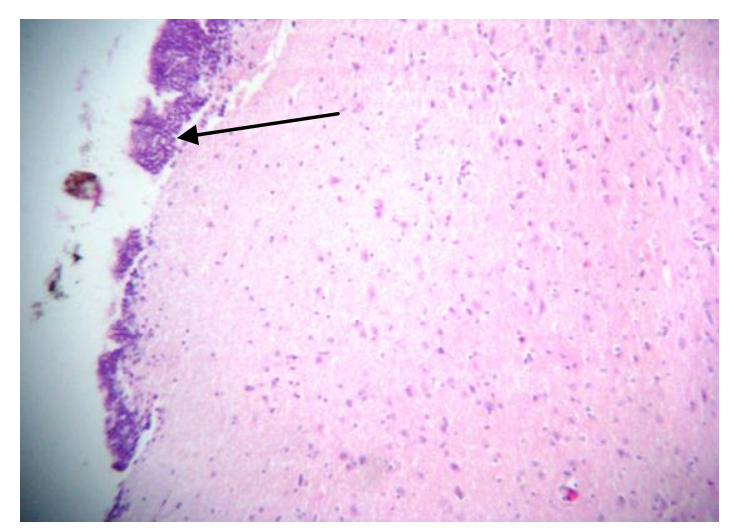

Fig (13): brain at day 2 pi. reveals lymphocytic infiltration in the meningies ( $\longleftarrow)$ ( H\&EX10).

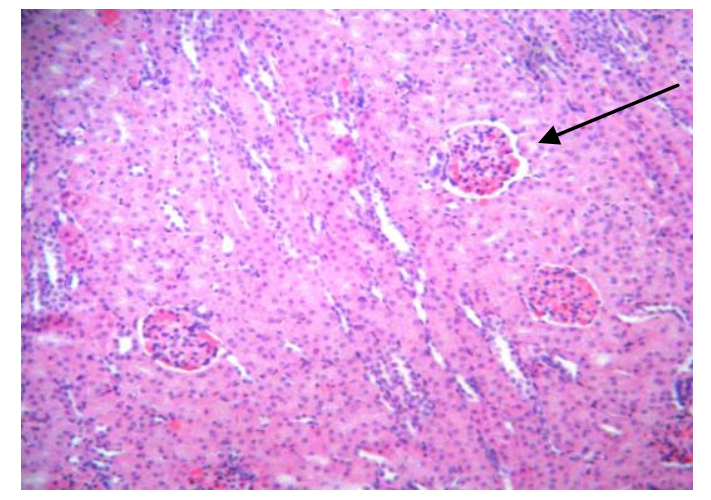

Fig (10): Kidney at $16 \mathrm{hr}$ showed hypercellulirty of the glomeruli $(\leftarrow)$ with congestion of blood capillaries of the glomerular tuft ( H\&EX10).

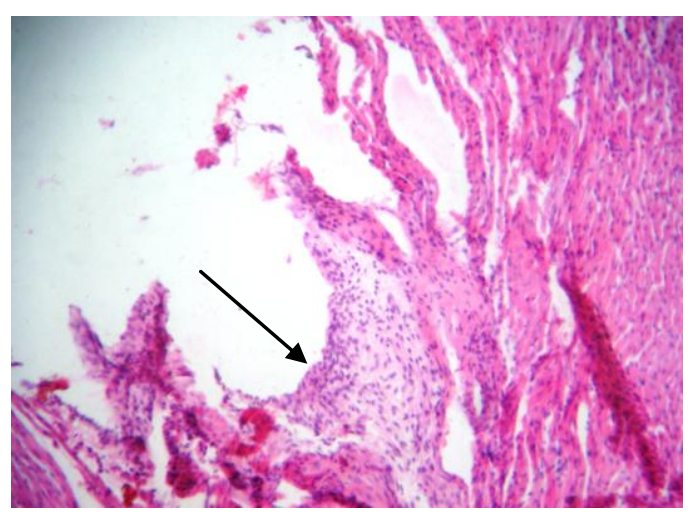

Fig (12): heart at day 6 pi. showed thickening of the endocardium layer $(\rightarrow)$ due to hyperplasia of the endothelial cells lining \& also fibrinous exudates in addition to inflammatory cells infiltration( H\&EX10).

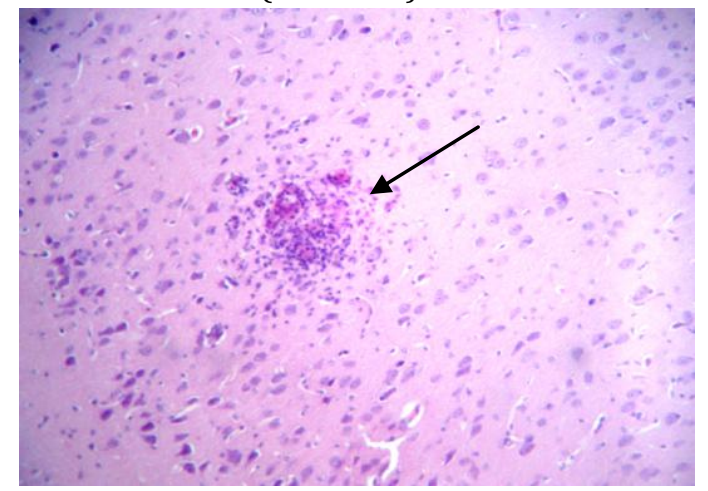

Fig (14):brain at day 6 pi. showed microgliosis $(\longleftarrow \quad) \quad(H \& E X 10)$. 


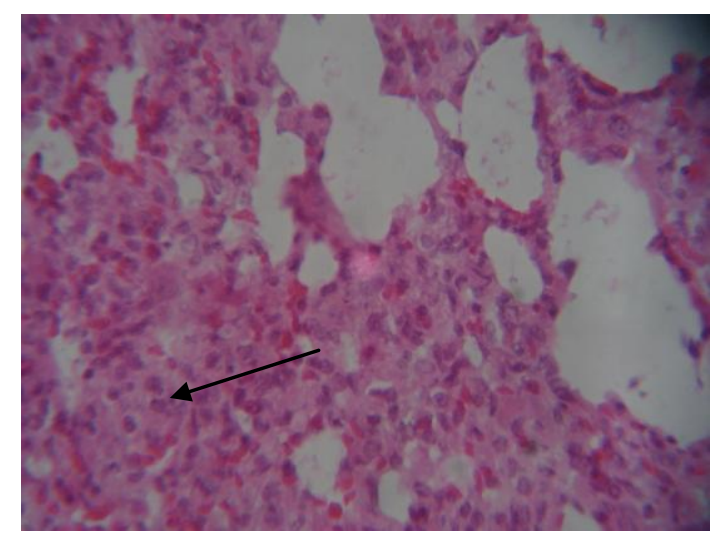

Fig (15): lung at day 6 pi. revels thickening of the inter- alveolar wall due to inflammatory cells \& fibranous exudates ( $\longleftarrow$ ) ( H\&EX10).

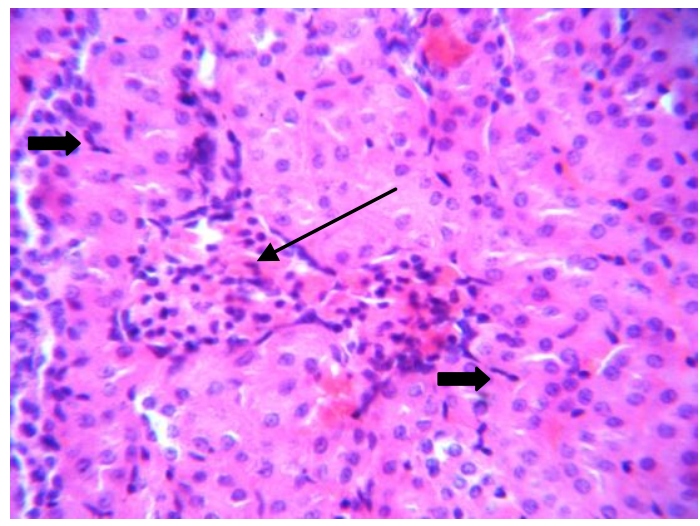

Fig (17):kidney atday 3 pi. showed hyper cellularty of the glomerli $(\longleftarrow)$ with moderate hyperplasia of the endothelial lining of the capillaries between renal tubules ( $)$ ( H\&EX40).

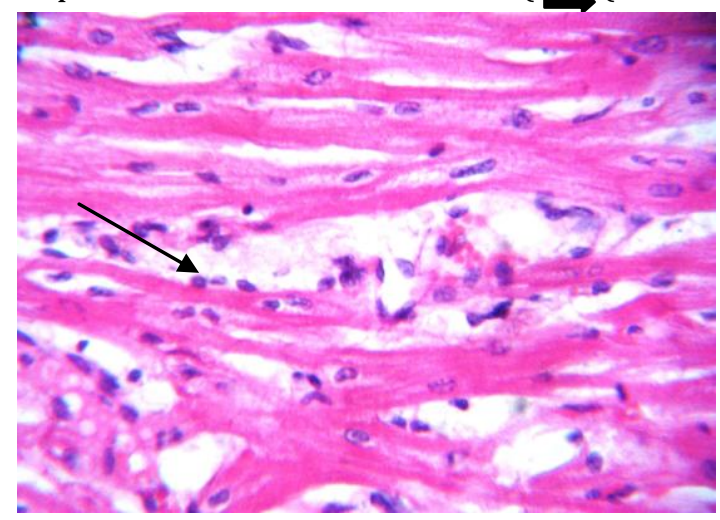

Fig (19): heart at day 9 pi. revel inflammatory cells infiltration between muscles fiber $(\rightarrow)$. ( H\&EX10).

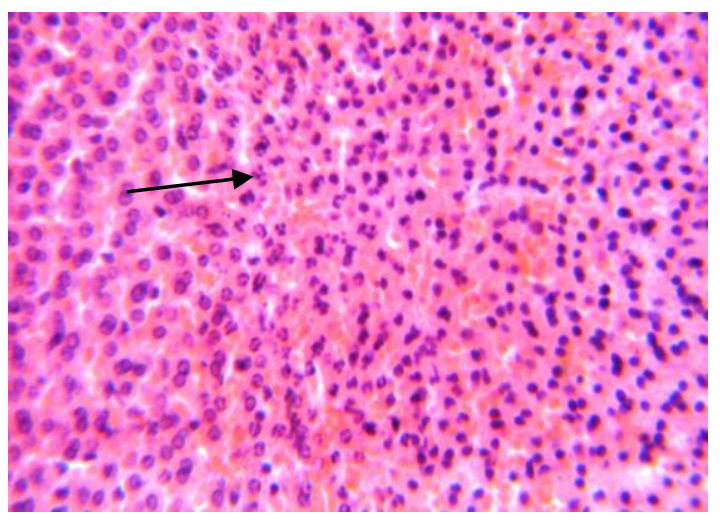

Fig (16): liver at day 3 pi. showed sever infiltration of polymorph-nuclear cells $(\rightarrow)$ between swollen hepatocytes ( H\&EX40).

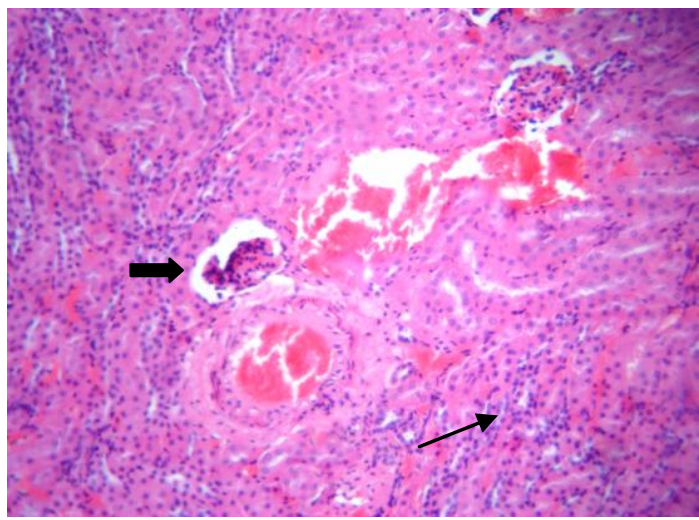

Fig (18): kidney at day 9 pi. showed inflammatory cells infiltration mainly lymphocyte between renal tubules $(\rightarrow)$ in addition to atrophy of some glomerali $(\Rightarrow$ ) (H\&EX10).

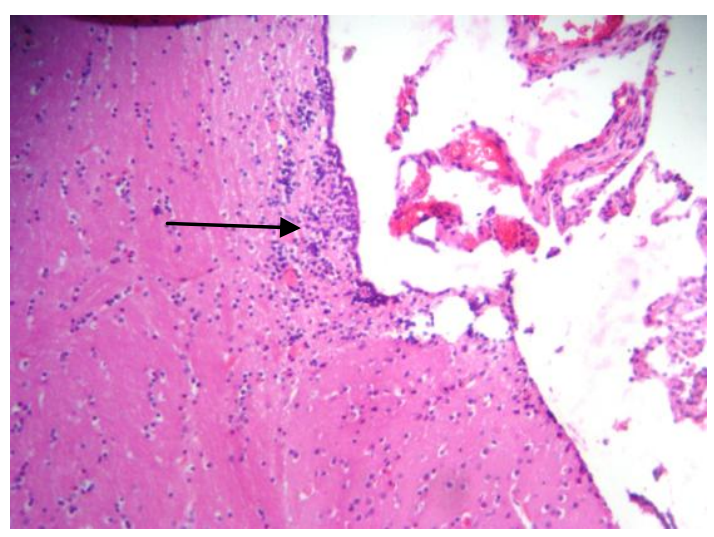

Fig (20): brain at day 9 pi. showed inflammatory cells infiltration $(\rightarrow)$ (H\&EX10). 
Nakamine (26) obtained two P. multocida isolates from muscovy ducks in Japan and carried out pathogenicity test in weaner rabbits and they died within $24 \mathrm{hrs}$, Histopathological study was carried out to observe the microscopic alteration induced by the organism in the tissue, They observed that multiple necrosis and bacterial aggregates were prominent in several organs, particularly in the liver. This result agreed with present observation in the liver which characterized by focal aggregations of lymphocyte in the liver parenchyma. Hyalourenase enzyme associated normally with invasive mechanism of bacteria (27)

Bhat (16) observed gross and microscopical changes in the tissues of pigeons which were died P. multocida infection. Postmortem examination revealed the liver and spleen were enlarged and mottled having hemorrhagic spots. Histopathologically the lesions in lungs showed edema and congestion. The liver revealed focal hepatitis surrounding the engorged vessels, as noticed by study. Das and Bhagman (28) found two isolates of P. multocida of sheep to be pathogenic to rabbits, on postmortem examination lesions including congestion of lungs, liver and kidney, hyperemia of intestine, congestion of mesenteric blood vessels, enteritis, congestion and haemorrhages on the myocardium and hemorrhagic tracheitis. That's agreed with our results.

Sujatha (29) recovered $30 \mathrm{P}$. multocida isolates from outbreaks in pig farm. Histopathological studies were carried out of vital organs of pig (heart, lung, liver kidney and intestine) to study the microscopic alterations induced by the organisms. Heart revealed congestion and hemorrhages. Congestion and edema were noticed in the lungs. Desquamations of superficial epithelial and mild congestion were seen in the intestine. Liver showed sever congestion, hemorrhages and degenerative changes in hepatic cell. Sever congestion and intertubular hemorrhages were noticed in kidneys.

Lesions of the acute form of the disease are typically of septicemia, including multiple hemorrhages through the serous surface in the myocardium, liver, and some time the lung. There may be a tracheatis, sub-acute cases shoe multiple necrotic lesions in the liver and spleen (30).

\section{References}

(1) Adlam C and Rutter JM (1989). Pateurella and Pasteurellosis. Academic Press, London. $341 \mathrm{pp}$.

(2)Quinn PJ Carter ME Markey B and Carter G R (1994). Pasteurella species. In: Clinical Veterinary Microbiology. 1st ed. Wolfe Publihings, Mosby - Year Book Europe Limited, London. 254-258.

(3)Manning PJ (1982). Serology of Pasteurella multocida in laboratory rabbits - a review. Laboratory Animal Sci. 32, 666-671.

(4)Takashima H Sakai H Yanai T and Masegi T (2001). Detection of antibodies against Pasteurella multocida using immunohistochemical staining in an outbreak of rabbit pasteurellosis. J. Vet Med Sci 63 171-174. 
(5)Delong D and Manning PJ (1994). Bacterial diseases. In: Manning P J, Ringler D H and Newcomer C E (eds.). TheBiology of the Laboratory Rabbit. 2nd ed. Academic Press, Inc., San Diego. 129-170.

(6)Maheswaran S K Thies E S (1979). Influenceofencapsualtion on phagocytosis of Pasteurella multocida by bovine neutrophils. Infection and Immunity, 26, 76-81.

(7)Glorioso JC Jones GW Rush HG, Pentler LJ Darif CA and Coward JE (1982). Adhesion of type A Pasteurella multocida to rabbit pharyngeal cells and its possible role in rabbit respiratory tract infections. Infection and Immunity. 35, 1103-1109.

(8)Rhoades KR and Rimler RB (1987). Effects of Pasteurella multocida endotoxins on turkey poults. Avian Diseases 31, 523-526.

(9)DiGiacomo RF Deeb BJ Giddens WE Bernard BL and Chengappa MM (1989). Atrophic rhinitis in New Zealand white rabbits infected with Pasteurella multocida. Ameri J Vet Res 50, 1460-1465.

(10)Straus DC Jolley WL and Purdy CW (1996). Characterization of neuraminidases produced by various serotypes of Pasteurella multocida . Infection and Immunity. 64, 1446-1449.

(11) Manning PJ DiGiacomo RF and DeLong D (1989). Pasteurellosis in Laboratory Animals. In: Pasteurellaand asteurellosis. New York, NY: Academic Press, Inc, p.265-302

(12) Luna LG (1968). Manual of histological staining methods of the armed forces institute of pathology. $3^{\text {rd }}$. ed., Mcgrow-Hill Book Company New York.

(13) Mils AA Misra SS and Irwin, J (1938). The estimation of the bactericidal powerof blood. J Hyg 38:732-748.

(14)Patel HK (2004). Biomedical characterization, antimicrobial sensitivity PCR-based detaction and mouse pathogenicity of Pasteurella multocida feiled isolates. Department of Veterinary Microbiology College of Veterinary Science and Animal Husbandry Anand Agricultural University.

(15) Satinati SN Zuki AB, Saad MZ Hazmi A J and Po SP (2006). The response of Gut associated lymphoid tissues (GALT) following Intranasal administration of p.multocida B2 in rats. J Ani Vet Advan Medwell Journals. 5 (11) : 1029-1034.

(16) Bhat MA Darzi MM Wani SA and Willayat, M (2002). Pathology of spontaneously occurring Pasteurella multocida infection in pigeons. Indian J Anim Sci 72:384-385.

(17) Rubin E and Farber JL (2000 ). Essential Pathology, 3rd Ed. Lippincott Williams and Wilkins, Philadelphia, PA.

(18) Uchiba M Okajima K Murakami K Johno M Mohri M Okabe H and Takatsuki K (1997). Rhs-TM prevents ET-induced increase in pulmonary vascular permeability through protein C activation Am J Physiol Lung Cell Mol Physiol 273:889-894.

(19) Lechner A J Velasquez A Knudsen KR Johanns CA Thomas F Tracy J and Matuschak GM (1998). Cholestatic liver injury increases circulating TNF- $\alpha$ and L-6 and mortality after Escherichia coli endotoxemia. Am J Respir Crit Care Med 157(5): $1550-1558$.

(20) Crespo E Macias M Pozo D Escames G Martin M Vives F Guerrero J M and Acuna-Castroviejo D (1999). Melatonin inhibits expression of the inducible NO synthase II in liver and lung and prevents endotoxemia in lipopolysaccharide induced multiple organ dysfunction syndrome in rats. The FASEB J. 13 : 1537-1546.

(21) Lawson JA Burn AR Farhood A Lynn-Bajt M Collins RG Smith CW and Jaeschke H (2000). Pathophysiologic importance of E-and L-selectin for neutrophile-induced liver injury during endotoxemia in mice. Hepatology. 32(5):990-998. 
(22) Harish BR Shivaraj BM Chandranaik BM Venkatesh MD and Renukaprasad C (2009). Hemorrhagic septicemia in Asian elephants elephas maximus in Karnataka state, india J of Threatened Taxa 1(3): 194-195.

(23) Gourlay RN Thomas LH Wyld SG (1989). Experimental Pasteurella multocida pneumonia in calves. Res Vet Sci 47(2):185-9.

(24) Blood DC and Handerson JA ( 1974). Veterinary medicine $4^{\text {th }}$ ed. P 367.

(25) AL-HADDAWI MH JASNI S ISRAF DA ZAMRI-SAAD M MUTALIB AR and SHEIKH-OMAR AR (2001). Ultrastructural pathology of nasal and tracheal mucosa of rabbits experimentally infected with Pasteurella multocida serotype D:1. Volume 70, Issue 3, Pages 191-197.

(26) Nakamine M Ohshriro M Ameku M Ohshiro K KerumaT Sawada T and Ezaki T (1992). Outbreak of fowl cholera in muscovy ducks in Japan. J Vet Med sci 54:12251227.

(27) Rimler RB and Rhoades KR (1994). Hyaluronidase and chondroitinase activity of Pasteurella multocida serotype B:2 involved in hemorrhagic septicaemia. The Vet record 134(3):67-8.

(28) Das SS and Bhagwan PSK (1997). Isolation and characterization of Pasteurella multocida from ovine pneumonia. Indian J Anim Sci 67:29-30.

(29) Sujatha K Srilatha CH and Ahmed NN (2003). An outbreak of pasteurellosis in pigs. Indian Vet J 80:341-343.

(30) Buxton A and Fraser G (1977) animal microbiology. Vol. 1. P 122-125. 